
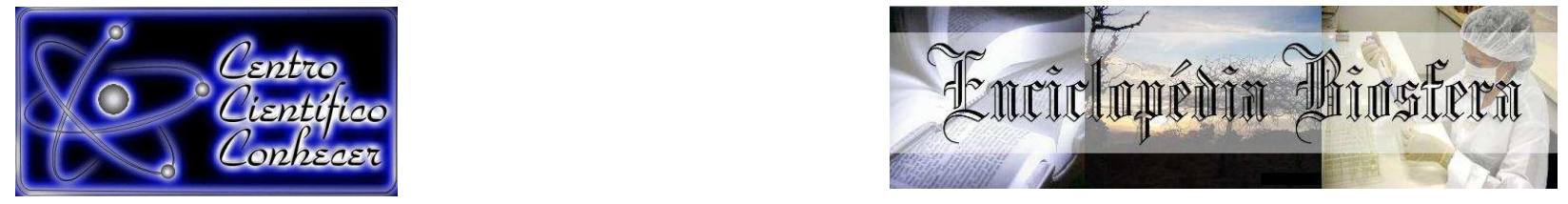

\title{
EFETIVIDADE DE MANEJO DE RESERVAS PARTICULARES DO PATRIMÔNIO NATURAL MUNICIPAIS: O CASO DA RPPNM AIRUMÃ, CURITIBA/PR
}

\begin{abstract}
Marília Thiara Rodrigues Basniak¹, Ronaldo Viana Soares ${ }^{2}$, Alexandre França Tetto², Mariana Meira ${ }^{3}$.

${ }^{1}$ Mestranda no programa de pós-graduação em Engenharia Florestal da Universidade Federal do Paraná - UFPR (mariliabk@gmail.com) Curitiba - Brasil. 2Professor Doutor do Departamento de Ciências Florestais - UFPR. ${ }^{3}$ Graduanda de Engenharia Florestal - UFPR.
\end{abstract}
Recebido em: 08/09/2015 - Aprovado em: 14/11/2015 - Publicado em: 01/12/2015 DOI: http://dx.doi.org/10.18677/Enciclopedia_Biosfera_2015_147

\begin{abstract}
RESUMO
O município de Curitiba possui cerca de $20 \%$ de sua superfície coberta por floresta, sendo que $75 \%$ dessas áreas estão situadas em propriedades particulares. Essas áreas contribuem para vários aspectos ambientais, tais como: equilíbrio climático, qualidade do ar, conservação da água, manutenção da flora e fauna, controle de erosão e retenção de sedimentos. Por isso, instrumentos que estimulem a manutenção e conservação dessas áreas são necessários, como por exemplo, a criação de áreas naturais protegidas. Porém, a criação de uma área natural protegida não é garantia de proteção efetiva, uma vez que a gestão e a análise da efetividade do manejo são essenciais. O objetivo deste trabalho foi avaliar a efetividade de manejo da Reserva Particular do Patrimônio Natural Municipal (RPPNM) Airumã, do município de Curitiba/PR, de acordo com o método denominado Efetividade de Manejo de Áreas Protegidas (EMAP). Para isso foram utilizados dados sobre a gestão da reserva fornecidos pela proprietária, em entrevista, sobre os seguintes aspectos: planejamento e ordenamento, administrativo, conhecimento, qualidade dos recursos naturais e usos atuais. A RPPNM Airumã registrou $68 \%$ de efetividade de manejo, o que é considerado um padrão mediano de qualidade de gestão de acordo com a escala adotada. Como ponto forte da gestão podem-se destacar os usos atuais da reserva, pois não existem usos não permitidos, e os usos permitidos são compatíveis com os objetivos da reserva. Como âmbito mais fraco da gestão pode-se citar o administrativo, pois não existem funcionários e as instalações administrativas existentes necessitam de reformas.
\end{abstract}

PALAVRAS-CHAVE: Manejo de áreas protegidas; reserva particular do patrimônio natural municipal; unidade de conservação. 


\title{
MANAGEMENT EFFECTIVENESS OF PRIVATE MUNICIPAL NATURAL PATRIMONY RESERVES: THE CASE OF RPPNM AIRUMÃ
}

\begin{abstract}
Curitiba's county has about $20 \%$ of its surface covered by forests, and $75 \%$ of this area is located in private properties. These areas contribute to many environmental aspects, such as: climate equilibrium, air quality, water conservation, fauna and flora maintenance, erosion control and sediment retention. That is why instruments which stimulate the conservation and maintenance of these areas are necessary, for example, to the establishment of natural protected areas. However, the creation of a natural protected area is not guarantee of an effective protection, because the management and the management effectiveness analysis are also essential. The main objective of this work was to assess the management effectiveness of the Airumã's Natural Private Reserve (RPPNM) in the municipality of Curitiba, PR, according to the Protected Areas Management Effectiveness (EMAP) method. Data from the reserve management were provided by the owner, in an interview about the following aspects: planning and ordering, administration, knowledge, quality of natural resources, and current uses. The Airumã's RPPNM presented a management effectiveness of $68 \%$, according to the chosen scale, which is considered an average quality level. The current uses of the RPPNM can be considered the strongest point of the management, because there were no prohibited uses and the permitted ones were compatible with the reserve's objective. The weakest management point was the administration, because there were no employees working in the reservation, and the existent administration infrastructure needs renovation.
\end{abstract}

KEYWORDS: management of protected areas; municipal natural patrimony private reserve; conservation unit

\section{INTRODUÇÃO}

A análise da efetividade de manejo de unidades de conservação pode oferecer aos formuladores de políticas públicas ambientais uma importante ferramenta para identificar as principais tendências da área e os aspectos que necessitam ser considerados para melhorar a gestão de uma unidade de conservação, de um grupo, ou até mesmo do sistema de unidade de conservação (KINOUCHI et al. 2012).

O manejo de uma área protegida é definido como o conjunto de ações e atividades necessárias ao alcance dos objetivos das unidades de conservação, incluindo as atividades fins como proteção, recreação, educação, pesquisa e manejo dos recursos, bem como as atividades de administração ou gerenciamento (BRASIL, 2006). De acordo com IZURIETA (1997) e CIFUENTES et al. (2000), a efetividade do manejo é considerada como o conjunto de ações que, com base em habilidades, capacidades e competências particulares, permitem cumprir satisfatoriamente a função para a qual a área protegida foi criada.

Ações de conservação da natureza em propriedades privadas são consideradas uma importante estratégia para a proteção da biodiversidade (LANGHOLZ, 1996; LANGHOLZ \& LASSOIE, 2001). Segundo PRIMACK \& RODRIGUES (2005), reservas pequenas, localizadas próximas a áreas habitadas, podem servir de excelentes centros de estudos da natureza e educação para conservação. Além desta vantagem, reservas pequenas e bem localizadas podem incluir uma grande variedade de habitats e mais populações de espécie raras do que 
seria possível em uma grande extensão na mesma área (SIBERLOFF \& GOTELLI, 1984).

De acordo com o Sistema Nacional de Unidade de Conservação, a Reserva Particular do Patrimônio Natural (RPPN) é uma unidade de conservação de uso sustentável, instituída em áreas privadas, gravada com perpetuidade, que tem como objetivo conservar a diversidade biológica (BRASIL, 2000). Dadas as ameaças correntes à biodiversidade e as reduções nos investimentos públicos em áreas protegidas, LANGHOLZ (2002) afirma que é necessário caracterizar as reservas particulares e avaliar sua contribuição potencial para a conservação da biodiversidade.

Consideradas como o conjunto de áreas interurbanas que apresentam cobertura vegetal, as áreas verdes urbanas contribuem de modo significativo para a qualidade de vida e para o equilíbrio ambiental das cidades (BRASIL, 2015).

Sendo assim, desde a década de 70 o poder público de Curitiba vem implementando políticas municipais e mecanismos legais e fiscais a fim de conservar todas estas áreas verdes, sejam elas privadas ou públicas (PANASOLO et al., 2014). Apesar de ser uma metrópole, Curitiba possui cerca de $20 \%$ da área do município recoberta por floresta, equivalendo a mais de 78 milhões de metros quadrados. $E$ cerca de $75 \%$ dessa área ainda recoberta por florestas está situada em propriedades particulares e $25 \%$ encontra-se em áreas públicas (PREFEITURA MUNICIPAL DE CURITIBA, 2013).

No ano de 2000 foi decretada a Lei no 9.804, que cria o Sistema Municipal de Unidades de Conservação do Município de Curitiba (SMUC) (CURITIBA, 2000). No ano de 2006 a Lei do SMUC foi complementada com a Lei no 12.080 , a qual criou a Reserva Particular do Patrimônio Natural Municipal. Em janeiro de 2015, foi criada a Lei no 14.587, que reestruturou o programa das Reservas Particulares do Patrimônio Natural Municipal (CURITIBA, 2011). A primeira RPPNM de Curitiba foi criada em 2006, tendo sido denominada Cascatinha, e atualmente existem 15 RPPNMs em todo o município (APAVE, 2015).

De acordo com MACHADO (2007), o fortalecimento das RPPNs como ferramenta na conservação biológica depende de políticas públicas de apoio aos proprietários mais eficazes e de um incremento aos instrumentos econômicos de incentivo à criação, gestão e análise da efetividade do manejo destas reservas. Neste contexto, o objetivo deste trabalho foi avaliar a efetividade de manejo da RPPNM Airumã, a maior RPPNM do município de Curitiba.

\section{Caracterização da área}

\section{MATERIAL E MÉTODOS}

Localizada em Curitiba, a RPPNM Airumã está inserida no Bioma Mata Atlântica, na eco região da floresta com araucária ou Floresta Ombrófila Mista. Tal região tem sua delimitação fitogeográfica dada pela ocorrência do pinheiro-do-

paraná (Araucaria angustifolia), espécie característica da região e predominantemente presente nos planaltos do sul do Brasil (SOCIEDADE CHAUÁ, 2013).

A RPPNM Airumã, palavra de origem Tupi que significa "estrela da manhã" ou "estrela guia", foi criada no dia 21 de março de 2013, dia Internacional da Floresta, por meio do Decreto no 521. A Reserva Particular do Patrimônio Natural Municipal Airumã foi a $12^{\text {a }}$ RPPNM criada em Curitiba com a finalidade de contribuir para a preservação da biodiversidade urbana (AIRUMÃ ESTAÇÃO AMBIENTAL, 2015). 
Localizada no bairro de Santa Felicidade, a Airumã possui cerca de $30.000 \mathrm{~m}^{2}$ de floresta urbana, remanescente oriundo da floresta com araucária que se conecta com as áreas de floresta do Parque Tingui (Figura 1). De acordo com o decreto de criação, na RPPNM Airumã serão permitidas as atividades de pesquisa científica e visitação com objetivos turísticos, recreativos e educacionais e habitação unifamiliar.

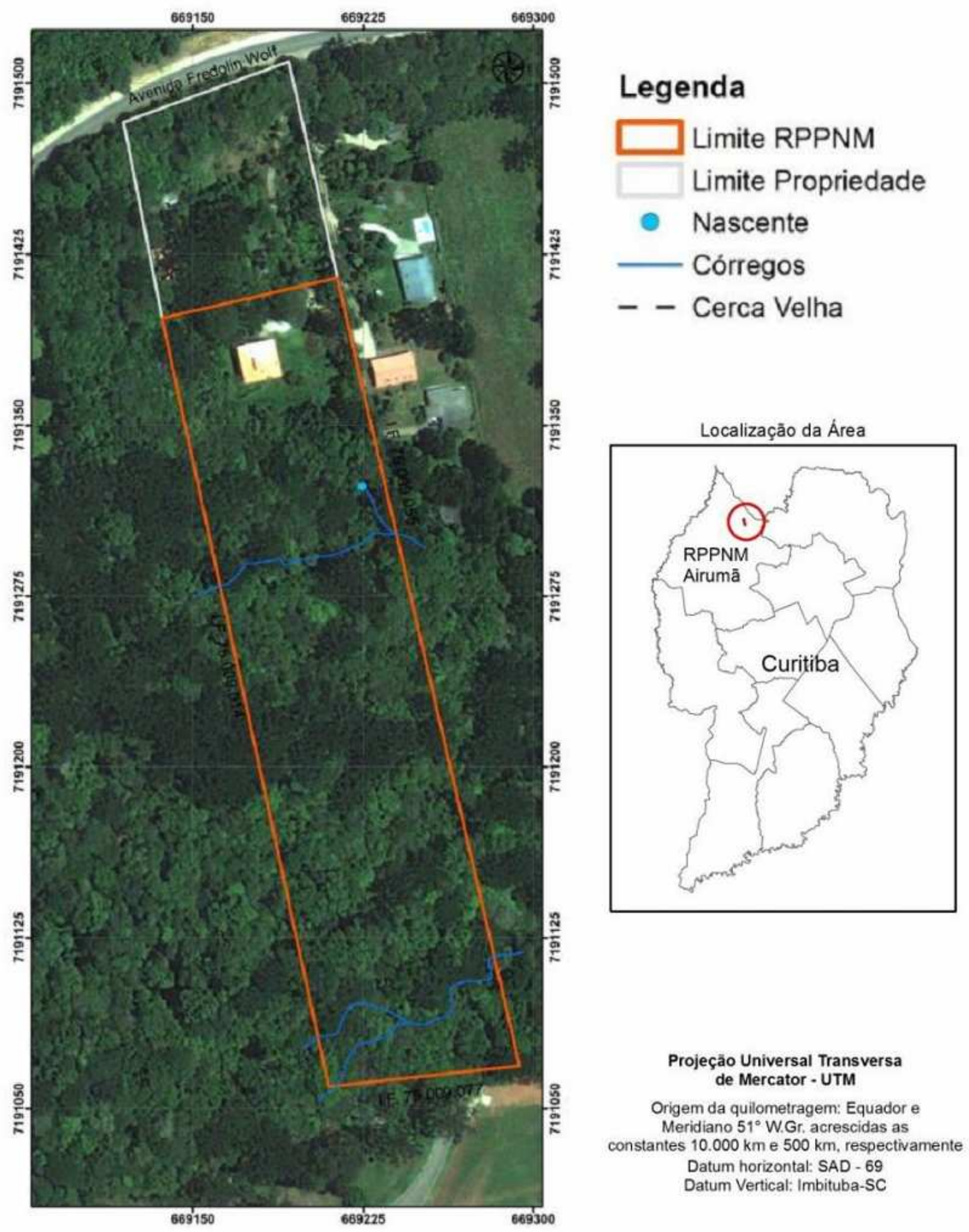

FIGURA 1 - Localização da área de estudo, dentro da RPPNM de Airumã no município de Curitiba/PR.

Fonte: adaptado de SOCIEDADE CHAUÁ (2013). 


\section{Processo metodológico}

A metodologia utilizada para se medir a efetividade da gestão da RPPNM foi a Efetividade de Manejo de Áreas Protegidas (EMAP), desenvolvida por CIFUENTES et al. (2000), sendo incorporadas adaptações propostas por FARIA (2004), PELLIN (2010) e pelos autores. Esta metodologia, segundo FARIA (2004), é eficaz e simples, podendo ser adotada para avaliar a gestão de qualquer categoria de manejo, permitindo comparações entre as unidades avaliadas.

A aplicação desta metodologia implica o uso de indicadores previamente selecionados, em acordo com os objetivos de manejo da categoria de gestão das unidades a serem avaliadas e a construção de cenários ótimos e atuais para cada indicador e associação destes a uma escala padrão, levando em consideração os seguintes âmbitos:

-Político e legal: avalia algumas questões relacionadas a questão política e legal, tais como: a questão do reconhecimento legal da área, a aplicação e cumprimento das normas, a relação com os moradores do entorno, a elaboração do relatório anual, ao apoio e relacionamento interinstitucional com o intuito de obter parcerias e o intercâmbio de informações com outras instituições ou reservas.

- Planejamento e ordenamento: avalia a existência de instrumentos de planejamento que proporcionem diretrizes adequadas para o alcance dos objetivos específicos de manejo da RPPNM, e mecanismos e meios que controlem e cumpram a função de ordenar as várias atividades desenvolvidas. As variáveis incluídas neste âmbito são: a existência, atualidade, características e nível de implementação do plano de manejo, os resultados dos programas de manejo, e se existe um zoneamento que defina as atividades que podem ser desenvolvidas em cada setor da unidade.

- Administrativo: está relacionado à capacidade do proprietário da área para gerir os recursos naturais protegidos, o que depende diretamente das condições e dos instrumentos que a área dispõe para conduzir ao alcance dos objetivos propostos para a RPPNM. As variáveis relacionadas a este âmbito são a existência de um administrador e funcionários e a capacitação destes para conduzir a reserva. Também refere-se a questão da demarcação física, avaliando a porcentagem do perímetro da unidade que se encontra demarcada, comparado ao perímetro demarcável.

- Conhecimento: considera a necessidade dos gestores das RPPNMs de terem informações biofísicas, cartográficas e socioeconômicas, que auxiliem no conhecimento sobre a região e sobre a unidade e que, desta forma, possam auxiliar em seu manejo. Aborda também a maneira como são tratadas as informações geradas pelas pesquisas desenvolvidas na unidade e se a unidade conta com algum sistema de monitoramento de fenômenos naturais, sociais e administrativos.

- Qualidade dos recursos naturais: são avaliados alguns fatores relacionados as características dos recursos naturais e integridade biológica da RPPNM, que podem ser determinantes para o cumprimento dos seus objetivos de manejo, tais como tamanho, forma e isolamento. Também é avaliada a porcentagem de área alterada 
em seu interior, as atividades desenvolvidas no entorno e as pressões sobre os recursos naturais.

- Usos atuais da RPPNM: são avaliados todos os usos da RPPNM, sejam eles permitidos (envolve atividades que são compatíveis com os objetivos de manejo da RPPNM e são executadas de forma apropriada para garantir que não extrapole a capacidade de suporte dos recursos naturais) ou não permitidos (envolve atividades que contrariam os objetivos de manejo e as normas da área, ou que estão sendo praticadas fora dos limites pré-estabelecidos, fora de zonas permitidas ou estão causando efeitos negativos para a UC).

Com base nos indicadores para avaliação do manejo das RPPNs, foi desenvolvido um roteiro de entrevista com o intuito de obter as respostas de todas as questões necessárias para avaliação do manejo da área. Este roteiro foi elaborado em forma de um questionário estruturado contendo 72 perguntas, sendo a maioria do tipo fechada.

A partir desse roteiro, foi realizada uma entrevista com a proprietária e gestora da RPPNM Airumã no mês de julho de 2015. Posteriormente, com estas informações, as matrizes com os cenários para avaliação do manejo foram preenchidas e analisadas.

O método de avaliação fundamenta-se na construção de cenários ou parâmetros de manejo, levando-se em conta âmbitos, variáveis e subvariáveis. De acordo com o recomendado por CIFUENTES et al. (2000) são chamados de "âmbitos" os indicadores de maior hierarquia e que permitirão visualizar aspectos globais do manejo. As "variáveis" são os indicadores de maior sensibilidade para descrever uma ação, atividade ou situação relacionada a um determinado âmbito. Já a "subvariável" é um indicador de certa especificidade, focado em uma ação, atividade ou situação relacionada a uma variável determinada.

Foram utilizados os cenários ótimos e atuais elaborados por PELLIN (2010) para cada indicador. Cada cenário foi associado a uma escala padrão onde o maior valor (número 4) corresponde à melhor situação e o menor valor (número 0) corresponde à pior situação possível de ocorrer no sistema.

QUADRO 1. Indicadores utilizados para a avaliação de manejo das RPPNMs

\begin{tabular}{|l|l|}
\hline \multicolumn{1}{|c|}{ Âmbito } & \multicolumn{1}{c|}{ Variáveis } \\
\hline Político e legal & Reconhecimento legal da RPPNM \\
\cline { 2 - 2 } & Aplicação e cumprimento das normas \\
\cline { 2 - 2 } & Relatório anual de acordo com o roteiro metodológico \\
\cline { 2 - 2 } & Relação com os moradores do entorno \\
\cline { 2 - 2 } ordenamento & Apoio e/ou relacionamento interinstitucional \\
\cline { 2 - 2 } & Intercâmbio \\
\hline Administrativo & Plano de manejo \\
\cline { 2 - 2 } & Programas de manejo \\
\cline { 2 - 2 } & Zoneamento \\
\hline & Administrador \\
\cline { 2 - 2 } & Corpo de funcionários \\
\cline { 2 - 2 } & Organograma, normas e procedimentos de gestão \\
\cline { 2 - 2 } & Infraestrutura e equipamentos \\
\cline { 2 - 2 } & Sustentabilidade financeira \\
\cline { 2 - 2 } & Demarcação física \\
\hline Conhecimento & Informação biofísica \\
\hline
\end{tabular}




\begin{tabular}{|l|l|}
\hline \multirow{5}{*}{$\begin{array}{l}\text { Qualidade dos recursos } \\
\text { naturais }\end{array}$} & Informações cartográficas \\
\cline { 2 - 2 } & Informações socioeconômicas \\
\cline { 2 - 2 } & Pesquisas e projetos \\
\cline { 2 - 2 } & Tamanhoramento e retroalimentação \\
\cline { 2 - 2 } & Forma \\
\cline { 2 - 2 } & Isolamento \\
\cline { 2 - 2 } & Porcentagem de área alterada em seu interior \\
\cline { 2 - 2 } & Atividades desenvolvidas no entorno \\
\cline { 2 - 2 } & Pressões sobre os recursos naturais \\
\hline Usos atuais & Usos permitidos \\
\cline { 2 - 2 } & Usos não permitidos \\
\hline
\end{tabular}

Fonte: adaptado de PELLIN (2010).

Os dados obtidos pela entrevista foram tabulados em planilha eletrônica Excel, onde foram calculados os totais ótimos, os totais alcançados e os valores percentuais para cada âmbito analisado, para os indicadores e para o sistema como um todo. Estes valores percentuais foram comparados à escala de qualificação da eficácia da gestão apresentada na tabela 1 e, desta forma, foi feita a classificação da eficácia da gestão da unidade e dos âmbitos ou variáveis analisadas.

TABELA 1. Escala de qualificação da eficácia da gestão das unidades de conservação

\begin{tabular}{|c|c|c|}
\hline $\begin{array}{c}\text { Total } \\
\text { ótimo (\%) }\end{array}$ & $\begin{array}{c}\text { Nível de } \\
\text { qualidade } \\
\text { do manejo }\end{array}$ & Descrição do padrão de qualidade \\
\hline$\leq 40,99$ & $\begin{array}{l}\text { Padrão muito } \\
\text { inferior }\end{array}$ & $\begin{array}{l}\text { Faltam elementos básicos para a gestão e essa situação } \\
\text { não garante a permanência da unidade em longo prazo, o } \\
\text { que obriga o proprietário a ter maiores esforços. Nas atuais } \\
\text { condições, os objetivos de manejo podem não ser } \\
\text { alcançados. }\end{array}$ \\
\hline $41-54,99$ & $\begin{array}{l}\text { Padrão } \\
\text { inferior }\end{array}$ & $\begin{array}{l}\text { A área é vulnerável a fatores externos e/ou internos, } \\
\text { contando apenas com os elementos mínimos necessários à } \\
\text { sua gestão, o que pode acarretar o descumprimento de } \\
\text { alguns dos objetivos primários da área. }\end{array}$ \\
\hline $55-69,99$ & $\begin{array}{l}\text { Padrão } \\
\text { mediano }\end{array}$ & $\begin{array}{l}\text { A unidade apresenta deficiências muito pontuais, mas que } \\
\text { interferem na constituição de uma base sólida para o efetivo } \\
\text { manejo. Alguns dos seus objetivos secundários podem ser } \\
\text { desatendidos. }\end{array}$ \\
\hline $70-84,99$ & $\begin{array}{l}\text { Padrão } \\
\text { elevado }\end{array}$ & $\begin{array}{l}\text { Os fatores e meios para a gestão existem e as atividades } \\
\text { essenciais são desenvolvidas normalmente, tendendo o } \\
\text { conjunto em direção aos objetivos da unidade. As principais } \\
\text { ações programáticas são realizadas. }\end{array}$ \\
\hline$\geq 85$ & $\begin{array}{l}\text { Padrão de } \\
\text { excelência }\end{array}$ & $\begin{array}{l}\text { A área possui todos ou quase todos os componentes-chave } \\
\text { para sua gestão efetiva, podendo absorver demandas e } \\
\text { exigências futuras sem comprometer a conservação dos } \\
\text { recursos protegidos. O cumprimento dos objetivos está } \\
\text { assegurado. }\end{array}$ \\
\hline
\end{tabular}

Fonte: Faria (2004)

\section{RESULTADOS E DISCUSSÃO}

A RPPNM Airumã registrou 68\% de efetividade de manejo, o que de acordo com a classificação proposta por FARIA (2004) é considerado um padrão mediano 
(55 a 69,99\%) de qualidade de gestão. Isso significa que esta unidade de conservação apresenta problemas pontuais que interferem no efetivo manejo e no alcance dos seus objetivos.

Não existem muitos estudos relacionados à caracterização e avaliação da efetividade de manejo de reservas particulares no Brasil. Um deles foi realizado por MESQUITA (1999), que avaliou o manejo de quatro reservas privadas do Brasil e duas da Costa Rica. Das reservas do Brasil, o autor concluiu que apenas uma, a Reserva Natural Salto Morato, era classificada como um padrão elevado de gestão, de acordo com escala utilizada. As outras três áreas, Estação Veracruz, Fazenda Bom Retiro e Ecoparque de Uma, enquadraram-se em um padrão mediano de gestão. Outro estudo, realizado no estado do Mato Grosso por PELLIN (2010), mostrou que $17,6 \%$ das RPPNs daquele estado também possuem um padrão mediano de gestão.

\section{Resultados da avaliação em função dos âmbitos e variáveis analisadas}

\section{Político e legal}

Neste âmbito a RPPNM Airumã registrou $58 \%$ do seu total ótimo. No aspecto político, a unidade tem uma boa capacidade de articulação com outras unidades e atualmente possui apenas um parceiro, a Universidade Federal do Paraná, que atua no desenvolvimento de pesquisas.

A proprietária da unidade é a atual presidente da Associação de Proprietários de Áreas Verdes de Curitiba e Região Metropolitana (APAVE), participando com frequência das reuniões, e está filiada à Confederação Nacional de Reservas Particulares do Patrimônio Natural (CNRPPN). Além disso, também frequenta reuniões relacionadas à conservação da natureza, realizadas pela Secretaria Municipal do Meio Ambiente de Curitiba. A reserva também realiza ações de divulgação junto a sociedade, através de palestras, jornais, rádio e redes sociais da internet.

Sobre o aspecto legal, a reserva elaborou todos os documentos necessários para a criação de uma RPPNM, portanto não apresenta problemas jurídicos relacionados ao processo de reconhecimento da área, possui o memorial descritivo e está averbada na matrícula do imóvel. Atualmente, conta com um incentivo relacionado a isenção de IPTU e com uma certidão de venda de potencial construtivo. Com esta certidão, o proprietário pode transferir o direito que tem de construir na unidade para outro local que não tenham restrições ambientais, respeitando os parâmetros previstos na legislação específica (PREFEITURA MUNICIPAL DE CURITIBA, 2013).

O roteiro para criação e elaboração do plano de manejo e conservação de Reservas Particulares do Patrimônio Natural Municipal de Curitiba, solicita a elaboração do relatório anual contendo a avaliação da efetividade da área para a conservação da biodiversidade, especificando quais atividades estão sendo desenvolvidas no local, e qual a aplicação do recurso financeiro eventualmente destinado à manutenção da área (PREFEITURA MUNICIPAL DE CURITIBA, 2013). Este relatório não está sendo elaborado anualmente por falta de conhecimento e de recursos financeiros.

Planejamento e ordenamento 
A RPPNM Airumã tem como principais objetivos de manejo conservar espécies e ecossistemas, conservar rios, promover a pesquisa, promover a educação ambiental, conservar a beleza cênica, proteger os recursos culturais e promover atividades de capacitação. Isso corrobora com MESQUITA (1999) e PELLIN (2010), que relatam como objetivo principal do manejo questões conservacionistas e sociais, como a conservação de espécies e educação ambiental.

Neste âmbito, a unidade registrou $68 \%$ do total ótimo. Como pontos positivos, pode-se mencionar que a reserva possui um plano de manejo recentemente elaborado, que contém uma descrição completa das características físicas, sociais e biológicas, um zoneamento compatível com as características da área e os programas de manejo com diretrizes claras para o manejo da reserva. CEGANA et al., (2007) verificaram que entre as 66 RPPNs do Paraná avaliadas em seu trabalho, quase $90 \%$ não possuíam plano de manejo. MESQUITA (1999) relatou que dentre 118 reservas privadas da América Latina que participaram da sua pesquisa, 40\% contavam com um plano de manejo, tendo sido constatado pela WWF (2014) que $52 \%$ das RPPNs do estado de São Paulo não tinham este documento.

Porém, o nível de implementação deste plano está entre 31 e 50\%, sendo que alguns programas, tais como o programa de administração, de sustentabilidade econômica e o de uso público, estão com menos de $50 \%$ de suas atividades implementadas.

Vale destacar que todas as RPPNMs criadas no município de Curitiba contam com o plano de manejo, pois no processo para a criação é formalizado um termo de compromisso entre a Secretaria Municipal do Meio Ambiente (SMMA) e o proprietário da área, onde este se compromete a apresentar o plano de manejo e conservação da RPPNM, elaborado conforme roteiro metodológico em um prazo máximo de 180 dias após a data de assinatura do decreto de criação da RPPNM (PREFEITURA MUNICIPAL DE CURITIBA, 2013).

\section{Âmbito administrativo e conhecimento}

Este âmbito é o mais crítico da reserva, apresentando $42 \%$ do total ótimo. Este resultado foi o mais baixo, pois a unidade tem apenas a administradora, que também é a proprietária da unidade, e mais nenhum outro funcionário específico disponível; somente diaristas que realizam atividades em seu interior quando necessário. A reserva necessita da contratação de pelo menos um funcionário específico para prestar serviços de manutenção. Sendo assim, a reserva não possui uma estrutura organizacional mínima para o desenvolvimento das atividades administrativas, além de não contar também com normas e procedimentos de gestão bem definidos.

Sobre a situação atual da RPPNM com relação à suficiência dos recursos financeiros, o proprietário tem interesse em gerar recursos na área, mas não possui estrutura administrativa e legal para isso, sendo o provedor das necessidades básicas de manejo da área atualmente.

Em relação a infraestrutura, existe a sede para a administração, o centro de visitantes, o centro de pesquisa, o centro de educação ambiental, um alojamento para pesquisadores e trilhas, porém todos estes locais necessitam de ampliação ou reforma. E ainda há a necessidade de construção de trilhas, decks e implantação de placas de sinalização. PELLIN (2010), neste item, obteve 53,5\% do ótimo para as 
reservas do estado do Mato Grosso. MESQUITA (1999) obteve uma média de 80,5\% para as seis reservas privadas analisadas.

No âmbito conhecimento, a RPPNM obteve $75 \%$ do total ótimo. As informações biofísicas, socioeconômicas e cartográficas contidas no plano de manejo estão disponíveis para utilização na área, servindo como subsídios para o manejo, muito embora as informações geradas por pesquisas desenvolvidas ainda são escassas e não estão acessíveis na unidade. O resultado observado por MESQUITA (1999) para as seis reservas que compuseram o seu estudo, foi de $85 \%$ para esse item. Conforme PELLIN (2010), este item é considerado um dos piores nas reservas do estado do Mato Grosso, para o qual obteve 36\%.

\section{Âmbito qualidade dos recursos naturais e usos atuais}

A qualidade dos recursos naturais atingiu $79 \%$ do total. Este resultado apresentado está acima do que PELLIN (2010) encontrou nas reservas do Mato Grosso, com 59,3\% do total ótimo, e MESQUITA (1999), avaliando seis reservas privadas, obtendo $44,45 \%$. Como pontos positivos pode-se mencionar que o entorno da unidade é formado principalmente por áreas naturais em poder de particulares, sendo que $70 \%$ estão conectados a outros remanescentes de vegetação nativa e menos de $5 \%$ da área está degradada, com atividades de recuperação.

O lado negativo para a qualidade dos recursos é a forma que a unidade possui, pois sendo retangular e com os quatro lados retos, os efeitos de borda são maiores. Segundo PRIMACK \& RODRIGUES (2005), as áreas que possuem forma circular minimizam a relação borda/área, pois o centro dessas áreas encontra-se mais distante das bordas do que qualquer outra forma. Mesmo as áreas quadradas são melhores do que as retangulares, pelo mesmo motivo mencionado acima.

O incêndio florestal, a contaminação ou poluição ambiental e as espécies exóticas se configuram como uma ameaça à unidade. Segundo PELLIN (2010), ameaça é definida como atividades ou infraestruturas que representam potencial de dano na área.

O incêndio florestal foi considerado um impacto alto caso aconteça, pois não existem ações para mitigar ou evitar os seus efeitos. Um impacto alto também pode vir da contaminação ou poluição, que pode ser causada por empreendimentos imobiliários próximos, caso estes realizem atividades que não cumpram com a legislação ambiental vigente. As espécies exóticas têm um impacto moderado caso ocorram na área, pois a unidade realiza ações periódicas de controle destas espécies.

Pressão é definida pelas atividades ou infraestruturas que incidem sobre a área, causando algum dano (PELLIN, 2010). A pressão urbana tem um impacto alto sobre a unidade e sua dinâmica é aumentar ao longo do tempo, por se tratar de uma área com grande interesse imobiliário (SOCIEDADE CHAUÁ, 2013).

\section{Usos atuais da RPPNM}

O âmbito "usos atuais" foi o que obteve a maior pontuação, com $88 \%$ do total ótimo, pois não existem usos não permitidos dentro da reserva. As atividades realizadas são compatíveis com os objetivos de manejo da unidade, porém o seu manejo técnico-administrativo é deficiente e as normas que as regulam são pouco claras. 
Dentre os itens analisados por PELLIN (2010), nas reservas do estado do Mato Grosso, este âmbito também foi o que atingiu a maior pontuação, ficando com $89,7 \%$ do total ótimo. MESQUITA (1999), avaliando os usos atuais de seis reservas privadas, encontrou um índice de $77,4 \%$ do ótimo em relação a esse quesito.

\section{CONCLUSÕES}

Com este trabalho, pode-se concluir que a RPPNM Airumã teve $68 \%$ de efetividade de manejo, o que de acordo com a classificação adotada, é considerado um padrão mediano de qualidade de gestão.

Como ponto positivo, a reserva possui todos os documentos necessários para a criação e gestão da área, além de todos os usos realizados serem permitidos pela legislação.

Embora a pontuação tenha ficado próxima do padrão elevado (70 a 84,99\%), a reserva possui deficiências em alguns âmbitos, que interferem na constituição de uma base sólida para o efetivo manejo, tais como administrativo e legal. A contratação de funcionários e a sua capacitação, a elaboração de um organograma contendo a estrutura organizacional, a busca pela sustentabilidade financeira e a elaboração do relatório anual são atividades essenciais para a garantia da efetividade de manejo desta unidade.

\section{AGRADECIMENTOS}

À Sra. Terezinha Vareschi, proprietária e gestora da RPPNM Airumã, pela disponibilidade, fornecimento de documentos relativos à Reserva e pela atenção dispendida durante esta pesquisa.

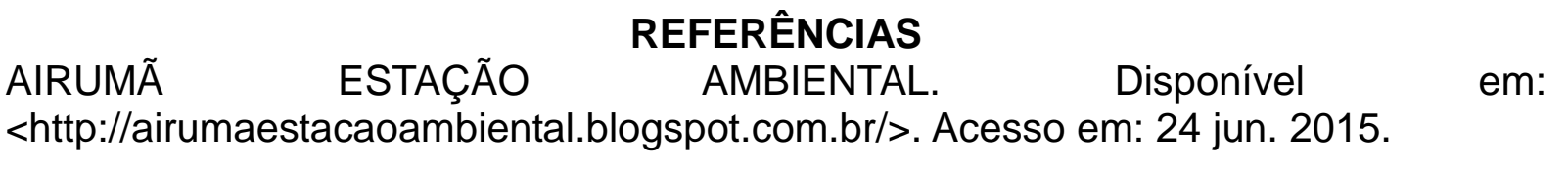

APAVE. RPPNMs oficializadas em Curitiba. Disponível em: <http://apavecuritiba.blogspot.com.br/p/14-rppnms-ficializadas-ate-abril-de.html.> Acesso em: 24 jun. 2015.

BRASIL. Lei no 9.985, de 18 de julho de 2000. Institui o Sistema Nacional de Unidades de Conservação da Natureza e dá outras providências. Disponível em: http://www.planalto.gov.br/ccivil_03/leis/l9985.htm. Acesso em: 20 mar. 2015.

Diretrizes para visitação em unidades de conservação - áreas protegidas do Brasil. Brasília, Ministério do Meio Ambiente, Secretaria de Biodiversidade e Florestas Diretoria de Áreas Protegidas, 2006.

. Parques e áreas verdes. Disponível em: <http://www.mma.gov.br/cidadessustentaveis/areas-verdes-urbanas/parques-e-\%C3\%A1reas-verdes>. Acesso em: 17 jun. 2015.

CEgANA, A. C. V.; TAKAHASHI, L. Y.; VIEIRA, F, G, D. Perfil das reservas particulares do patrimônio natural reservas particulares do patrimônio natural do estado do Paraná. Acta Sci, Agron. Maringá, v. 29, n. 2, p. 205 - 210, 2007. 
CIFUENTES, M.; IZURIETA, A.; FARIA, H. H. Medición de la efectividad del manejo de areas protegidas. Turrialba, Costa Rica. WWF; IUCN; GTZ, 2000. 105p.

CONDOMÍNIO DA BIODIVERSIDADE. RPPNM. Disponível em: <http://www.condominiobiodiversidade.org.br>. Acesso em: 20 jun. 2015.

CURITIBA. Lei $\mathbf{n}^{\circ} \mathbf{9 . 8 0 4}$ de $\mathbf{0 3}$ de janeiro de 2000. Cria o Sistema de Unidades de Conservação do Município de Curitiba e estabelece critérios e procedimentos para implantação de novas Unidades de Conservação. Disponível em: <http://multimidia.curitiba.pr.gov.br/2010/00086311.pdf>. Acesso em: 10 jul. 2015.

. Lei no 14.587, de 14 de janeiro de 2015. Reestrutura o programa das Reservas Particulares do Patrimônio Natural Municipal - RPPNM no município de Curitiba, revoga as leis oㅜ 12.080, de 19 de dezembro de 2006, e Lei oㅜ13.899, de 9 de dezembro de 2011.2 Disponível em: <https://leismunicipais.com.br/a/pr/c/curitiba/lei-ordinaria/2015/1458/14587/leiordinaria-n-14587-2015-reestrutura-o-programa-das-reservas-particulares-dopatrimonio-natural-municipal-rppnm-no-municipio-de-curitiba-revoga-as-leis-n-12080de-19-de-dezem >. Acesso em: 19 jul. 2015.

FARIA, H. H. Eficácia de gestão de unidades de conservação gerenciadas pelo Instituto Florestal de São Paulo, Brasil. 401 f. Tese (Doutor em Geografia). Universidade Estadual Paulista. Presidente Prudente, 2004.

IZURIETA, A. Evaluación de la eficiencia del manejo de áreas protegidas: validación de una metodología aplicada a un subsistema de áreas protegidas y sus zonas de influencia, en el Area de Conservación de Osa, Costa Rica. 126p. Tesis (Mag. Sc. Costa Rica), CATIE, 1997.

$\mathrm{KINOUCHI}, \mathrm{M}$. R. et al. Efetividade de gestão das unidades de conservação federais. Avaliação comparada das aplicações do método RAPPAM nas Unidades de Conservação federais, nos ciclos 2005-06 e 2010. Brasília: ICMBio \& WWFBrasil, 2012.

LANGHOLZ, J. Economics, objectives and success of private nature reserves in SubSaharan África and Latin América. Conservation Biology. v. 10, n.1, p. 271-280, 1996.

LANGHOLZ, J. Parques de propriedade privada. In: TERBORGH, J.; SCHAIK, C. V.; DAVENPORT, L.; RAO, M. Tornando os parques eficientes: estratégias para a conservação da natureza nos trópicos. Curitiba. Editora UFPR, 2002. p.197-212.

LANGHOLZ, J.; LASSOIE, J. Perils and promise of privately owned protected areas. BioScience. v.51, n. 12, p. 1079-1085, 2001.

MACHADO, M. Reservas particulares no estado de São Paulo: avaliação da efetividade na conservação da natureza. 165 f. Dissertação (Mestrado em Ciência Ambiental) - Universidade de São Paulo, São Paulo, 2007. 
MESQUITA, C. A. B. Caracterización de las reservas naturales privadas em américa latina. Dissertação. 120 f. (Mestrado em Ensino para o Desenvolvimento e Conservação) - Centro Agronômico Tropical de Investigación y Enseñanza, Turrialba, Costa Rica, 1999.

PANASOLO, A.; SILVA, J. C. G. L.; PETERS, E. L.; SANTOS, A. J. Áreas verdes urbanas privadas de Curitiba: uma proposta de valorização para conservação (estudo de caso). Enciclopédia Biosfera, Goiânia, v. 10, n. 19; p. 2731 - 2744, 2014.

PELLIN, A. Avaliação dos aspectos relacionados à criação e manejo de reservas particulares do patrimônio natural no estado do Mato Grosso do Sul, Brasil. Tese 227 f. (Doutorado em Ciências) São Paulo, Universidade de São Paulo, 2010.

PREFEITURA MUNICIPAL DE CURITIBA. Reserva Particular do Patrimônio Natural Municipal (RPPNM) em Curitiba - roteiro para criação e elaboração do plano de manejo e conservação. Curitiba, Prefeitura Municipal de Curitiba e Sociedade de Pesquisa em Vida Selvagem e Educação Ambiental - SPVS, 2013.

PRIMACK, R. B.; RODRIGUES, E. Biologia da conservação. 6 ed. Londrina: Planeta, 2005.

SIMBERLOFF, D. S.; GOTELLI, N. Effects of insularization on plant species richness in the prairie-forest ecotone. Biological Conservation, v. 29, p. $27-46,1984$.

SOCIEDADE CHAUÁ. Plano de manejo da Reserva Particular do Patrimônio Natural Municipal Airumã. Curitiba, 2013.

WWF. Sumário executivo. Diagnóstico das RPPNs do estado de São Paulo. Brasília, 2014. 